Pediat. Res. 2: 385-387 (1968)

\title{
Listening to Students
}

\author{
Presidential Address to The American Pediatric Society ${ }^{[1]}$
}

Alan Ross ${ }^{[2]}$

McGill University-Montreal Children's Hospital Research Institute, Montreal, Canada

When this Society was founded in 1888 , three of its founders were Canadians. Since then the bonds that have held us together have been so strongly and freely accepted as to be self-perpetuating. For you to have elected a Canadian president is, I like to think, a recognition of these bonds and of the Canadian contributions to American pediatrics. That it should have been my good fortune to come to this office is the greatly appreciated honor of a lifetime.

I have chosen to dwell briefly today on a professional hobby in which I have taken delight over the yearsListening to Students. For medicine has no commodity so essential, no standard of potential excellence so important, and no weather-glass so sensitive as our students.

They represent, as they always have, our academic currency. And though their opinions may be as difficult to evaluate as they are, at times, distressing, they do reflect in an amazingly accurate sense, I would submit, the current trend in a good deal of our thinking. Listening to this voice with its discords and its harmonies is a fascinating exercise.

In my day, and even long after, the voice was seldom heard outside student lounges, medical school residences, and medical student societies. Today there is a coherent expression of opinion, communicated in many ways from student to faculty, from one school to another, and it is rapidly growing in volume. It is beginning to influence, as it should, our own thinking about important aspects of curriculum planning, departmental organization and the attitudes of teachers, for it expresses the embryonic physician's point of view projected ten or more years ahead with a critical eye on the revolution taking place in society and on the needs of our children's children.

The voice is often destructively critical of our educational processes and assumes that new approaches to teaching are easily made. It so often expresses individual needs rather than the overall requirements of medical education. The student's experience is still a narrow one. But, to me, a vein of pure gold is to be recognized in the fact that his views are both provocative and challenging. We will do well to accept them as such, to examine them, refine and expand them, and avoid the development of antibodies leading to rejection.

As a Society, we have already recognized the value of this opinion by including a student in our symposia on medical education last year and again on tomorrow's program. Being individuals, I expect we tune in on our students in a variety of ways. I would like to describe some of my own sources of student opinion and to comment on some attitudes that seem to me interesting and useful.

But first I should note that all I have to say cannot be documented. If I were completely devoid of modesty and had less respect for art, in spite of the liberties it takes, I would maintain that listening to students and interpreting what they feel from what they say is an art, not a science. I would like you to consider these few remarks, then, merely as the rambling impressions of a lifetime of listening.

At McGill, we have been assigning all first- and second-year students in groups of four to clinical teachers, with no particular terms of reference except that meetings take place every fortnight in the hospital, the tutor's home, a quiet restaurant, or at times in an art gallery-anywhere that communication can be free and easy. In such informal settings, students of widely different home and cultural backgrounds frequently begin a delightfully free exchange of ideas. They cease to be just students and emerge as individuals, usually quite mature individuals coming into medicine with their undergraduate days behind them, not always intent on redeeming society, but on serving it. I $t$ is noteworthy that the benefit from these sessions, designed for the student, is more often than not reversed, for the tutor emerges with a new appreciation of 
the stresses involved in the student's rapid transition from a layman to a highly specialized professional.

Another interesting and useful listening post is provided by the editorial comments in student medical journals emanating from most of the medical schools here and, of particular interest, from many of the newer schools in emerging countries. News of student opinion comes back from Africa and Asia, too, through our own students who in increasing numbers are spending time abroad.

The student experience that I am sure is fascinating to us all comes from the mushrooming growth of the Student Health Organizations so effectively described here a year ago. You will recall that the movement began as recently as 1964 in Los Angeles with a group of 'health students', led by those studying medicine who had developed concern for the plight of the people living in poverty. Since then, the Organization has been gathering momentum until it is expected that some five hundred health students in medicine, dentistry, sociology, public health and other fields will spend this summer among the underprivileged members of our society in about fifty poverty areas in the United States and Canada. Their approach is interdisciplinary; their purposes both self-education and service. In light of our special interest in future forms of medical care and what we as medical educators can do in preparation for them, it is refreshing and encouraging that a dynamic segment of the student body has been selfpropelled into directly facing the reality of the needs of the poor. Will they be able to keep focused on present objectives? Will their challenges to society and to the programs in our medical schools aid in the solution of some of the problems now facing us in our seething city slums? Will their commitment to careers directed towards community medicine carry through to graduation and beyond? Does this buoyant movement hold promise of a partial answer to our manpower problem? Or will the minority among them succeed in diverting the mainstream of their effort away from the problems of poverty to which they have been dedicated from the beginning?

Students working in community programs have found great areas where disease prevention is almost unknown. Health education of the public in this regard, they discover, has been neglected in both our countries and especially, though not entirely, among the children of the poor. They assure us that all that is needed is reorganization and expansion of existing facilities, an essential part of which will be the provision of trained nonprofessional personnel.

All their reports from poverty areas emphasize the team approach, a trite phrase perhaps, but one that is hard to replace. From the beginning, the Student Health Organizations have been made up of so-called 'health students', only some of them medical. Some are training in dentistry, in nursing and in social work, or for careers in nutrition, in housing, in economics, and in population control. Experience has shown, too, that the medical man has not necessarily been the best person to lead the team, a concept perhaps long overdue.

Two years ago, the Association of Canadian Medical Colleges set up so-called 'Frontier Colleges' to provide a short summer exposure of a group of students to cultures different from their own. Some 75 such young people drawn from the thirteen Canadian medical schools have been transported, along with a few of their teachers, to far-flung spots such as Haiti and last year, Inuvik, above the Arctic Circle. These last have come back with a lively interest in and a new empathy for the plight of the Eskimo and the Indian. They encountered desperate social problems, including segregation, little incentive for primary or secondary education, and a degrading system of family subsidies that fits into no plans for the future. They found an infant mortality rate well above 100 deaths per thousand live births. Health services, inadequately supported, have reduced tuberculosis but are not winning the battle against venereal disease, alcoholism, and juvenile delinquency. The situation is unique and difficult, but at least these students had a good look at it, were shocked by a good deal of it, and are determined, one way or another, to contribute towards its improvement.

As these thoughtful students come back to their classrooms, laboratories, and clinics, they bring with them criticism of our teaching methods that warrant, at the very least, some consideration. In some schools, students still find an abundance of formal lecturing, but too little group teaching and direct exposure to patients and their problems. Certain among them point to the failure of most public health teaching to fire the imagination and interest of the student. Problems of the community, they say, will have to be taught in the community if they are to have the appropriate impact upon the student. Some students are impressed by the importance of the humanities in clinical medicine and would like their teaching extended into the clinical years. Others would like to graduate with some experience in research and research methods, including those methods applicable to research in public health and community medicine. Many suggest that formal class instruction could be greatly enlivened by careful planning and by the employment of appropriate visual aids. All these ideas come through to the listening teacher, but the students yearn for more direct lines of communication to faculty, with representation on curriculum committees and direct communication with the Dean's office.

The student, too, deplores a busy impersonal atti- 
tude towards patients and their parents on the part of some of their teachers. He is critical when his teacher's interest in the disease seems to overshadow his interest in the patient. Given the opportunity, he will expound on the fact that disease is not an isolated entity but a biological phenomenon, involving families and communities and the genetic background from which the patient comes. He learns that the doctor alone can no longer meet the patient's needs in the face of today's comprehensive scientific medicine. We have been aware of most of these points for some time, but it seems to me healthy that our students can remind us that we have done nothing about a good many of them.

Students wonder why there are so relatively few outstandingly good teachers on our faculties and consider that some of those who have the most to give are ineffective in transmitting their knowledge. They ask what training one has to have to be a teacher. This is a good question. For as medicine broadens and becomes more and more dynamic, teachers with skills to meet these new challenges hold absolute key positions. Progress of scientific pediatrics is as dependent upon the skillful teaching and stimulation of students, residents, and fellows as it is upon research that gives life to that teaching.

The rapid advance of scientific knowledge is making it increasingly important that teachers be directly or indirectly, but continuously, exposed to active research programs. But they must be able as well to bring effectively to the bedside sociological and physiological approaches to problem solving. They must be, as Harry Medovy describes them, 'not mere regurgitators of facts, but catalysts who stimulate self-learning and the development of critical attitudes'. At the moment, for the most part, such people are either unusually gifted clinicians who have learned by experience the art of teaching, or are clinically trained scientific investigators working in a special field. Listening to senior students and residents, I sense an interest in clinical teaching as a career. There can be little doubt that the student material is there from which to recruit bright young people as professional teachers. They need to be carefully selected, and I think a good teacher can be recognized early. Their training will have to be as thorough and their position in the university and hospital as well recognized as that of scientific investigators. They will need instruction in medical teaching, perhaps in a Department of Medical Education, but they must also have a thorough grounding in clinical pediatrics and in the critical evaluation of data and theory that comes only through direct involvement in research. My point is that working alongside our teaching investigators we need to develop carefully chosen, well-trained, research oriented, professional clinical teachers in the pediatric field.
Allied to this thought is my impression that we have not kept pace with, nor have we taken advantage of, the valuable scientific advances being made in the field of education. Rapid changes in attitudes are taking place there, too. New techniques are being devised and sharpened; the processes by which we learn, store, and recall are becoming better understood. Evidence is accumulating that some of our present methods of teaching are out of date and amount to pleasant spoonfeeding of a pabulum with a short half-life. I am sure we all try to send the pediatrician home from a postgraduate course, not with a new technique or drug, but with a new stimulus to self-education that will grow, not shrink, over the years. But I wonder how often we succeed. To do so more effectively, we may have to turn to our teachers' colleges for help and to be truly ready to innovate, alter, and discard.

Now, what does all this mean to the American Pediatric Society? It means that there is value in evoking criticism and ideas from this outspoken activist student element. I like to think of these students as catalysts. They want to face more squarely than have their predecessors all the implications of social change going on around us and the basic issues that confront modern society. We must not only give them this opportunity; we must face some of these challenging problems ourselves.

But this is hardly enough. In this present period of unprecedented change, with rapidly advancing technology and automation and with increasing involvement of governments at all levels, new and better systems will have to be established if we are to bring the best of modern pediatrics to every child and every family within our reach. To succeed and survive, these systems will have to be built on the well-established foundation of medical education and research. It is quite clear that this will require the leadership both of this Society as a body and of its members as individuals, if we are to avoid the misfortune of errors being made by default. As this major realignment goes forward, the students want to be heard. They offer us a critical point of view that reflects, among other things, the voice of the community. Their criticism is largely constructive, and I feel we just must listen to what they have to say. For in the kind of world in which we find ourselves, for us to hold an ivory tower position would be to shirk important responsibilities to American pediatrics.

\section{Notes}

1. Delivered at the time of the Annual Meeting of the Society, May 1, 1968, in Atlantic City, New Jersey.

2. Requests for reprints should be addressed to: AlAn Ross, M.D., The Montreal Children's Hospital, 2300 Tupper Street, Montreal 25 (Canada). 